\title{
Da ortopedia à eficiência dos corpos: a gymnastica e as exigências da "vida moderna" (Minas Gerais, 1906-1930)
}

Tarcísio Mauro Vago*

\begin{abstract}
Resumo: $\mathrm{O}$ artigo trata da inserção da ginástica (Educação Física) nos programas de ensino primário em Minas Gerais, nas três primeiras décadas do século XX, discutindo representações que conformaram seu ensino. Neste período, teria ocorrido uma reconfiguração no seu primado orientador: se inicialmente a ginástica foi orientada como prática ortopédica de correção dos corpos de crianças, a década de 1920 parece trazer novas exigências para ela, articuladas às necessidades de organização do trabalho. É então que o primado da eficiência impõem-se como orientador de seu ensino. Da ortopedia à eficiência, a Educação Física refinava sua sintonia com a "vida moderna".

Palavras-chave: Ginástica, Educação Física, Escola, Corpo, História da Educação Física.
\end{abstract}

\section{Sob o primado da correção e constituição de corpos infantis: gymnastica como ortopedia}

Em pesquisa anterior, ${ }^{1}$ procurei mostrar que a Gymnastica foi escolarizada em Minas Gerais, nas primeiras décadas do século XX, sob o primado da correção, do endireitamento e da constituição dos corpos de crianças - isto é: como uma prática ortopédica. ${ }^{2}$ Seu enraizamento escolar foi então fertilizado com a reforma do ensino primário mineiro realizada em 1906, cujas principais

* Doutor em Educação (USP, 1999). Professor da Escola de Educação Física, Fisioterapia e Terapia Ocupacional da UFMG e do Programa de Pós-graduação Conhecimento e Inclusão Social em Educação da Faculdade de Educação da UFMG Membro do GEPHE - Grupo de Estudos e Pesquisa em História da Educação (FaE/ UFMG), e do CEMEF - Centro de Memória da Educação Física na UFMG.

1 Cf. VAGO, 2002

2 Estou aqui incorporando a proposição de Marta Carvalho da "metáfora da disciplina como ortopedia" para compreender "as práticas discursivas e institucionais que, no Brasil do final do século XIX até, pelo menos, a década de 1920, buscaram legitimação enquanto pedagogia moderna, científica ou experimental". (Cf. CARVALHO, 1997a.)

Movimento, Porto Alegre, v. 10, n. 3, p.77-97, setembro/dezembro de 2004 
novidades foram o advento dos Grupos Escolares e a prescrição de novos programas de ensino.

Esta reforma foi orientada pela crença de intelectuais e políticos republicanos mineiros de que a construção de uma nação e um Estado prósperos dependia, em grande parte, da tríade spenceriana "educação intellectual, moral e physica" do povo. Com o novo molde escolar pretendia-se não apenas instruir as crianças nos rudimentos das primeiras letras, mas educá-las nas boas maneiras e dar-lhes uma profissão: realizar assim o que o inspetor escolar José Rangel traduziu como "uma verdadeira revolução nos costumes, sob o ponto de vista moral, attingindo os beneficios della a propria vida economica", pois, "teremos em vez de um exercito de analphabetos a povoarem as officinas, um pessoal operario sufficientemente preparado para exercitar os seus misteres com intelligencia e aptidão". Esse operariado alfabetizado ofereceria "garantias de economia e incremento" à indústria que se tentava organizar em Minas e no País.

O sistema público de educação primária de Minas Gerais experimentou então um movimento de racionalização para dar conta de tarefas cada vez mais amplas e complexas, tendo "como finalidade última racionalizar o conjunto do social".

Um dos alvos centrais desse molde escolar foi o corpo das crianças: cultivar nelas um corpo belo, forte, saudável, higiênico, ativo, ordeiro, racional, em contraposição àquele considerado feio, fraco, doente, sujo e preguiçoso - esse o sentido alargado da "educação physica" que se queria realizar. Para tanto, da arquitetura imponente e majestosa prevista para a construção de prédios ao seu programa de ensino, a escola foi afirmada como um "templo de civilização" ${ }^{5}$ capaz de produzir os cidadãos republicanos desejados.

O programa para o ensino primário incluía "Leitura, Escripta, Lingua Patria, Arithmetica, Geographia, Historia do Brasil, Instrucção Moral e Civica, Geometria e Desenho, Historia Natural, Physica e Hygiene, Trabalhos Manuaes e Exercicios Physicos".

Para os "Exercicios Physicos", prescrevia-se no texto da reforma: "Não se descuide desta parte da educação das creanças na escola" pois deles dependia "o desenvolvimento physico dos futuros

3 Relatório de José Rangel, inspetor escolar em Juiz de Fora (MG). Cf. Arquivo Público Mineiro. Secretaria do Interior, Relatórios dos Grupos Escolares, 1907.

4 Cf. FARIA FILHO, 1995, p. 96.

5 Cf. SOUZA, 1998.

Movimento, Porto Alegre, v. 10, n. 3, p.77-97, setembro/dezembro de 2004 
cidadãos". A escola deveria assim proceder porque as crianças não teriam "em suas casas os meios e a occasião dos exercícios que a escola lhes pode proporcionar".

A escola era o lugar de realizar um programa racional de educação e cultivo dos corpos de crianças. Endireitar, corrigir, constituir e embelezar corpos: esse primado orientador da "gymnastica" como ortopedia encontra melhor tradução no relatório que a diretora Ignacia F. Guimarães, do "Grupo Escolar Henrique Diniz", de Belo Horizonte, apresentou ao Secretário do Interior, ao final do ano de 1915. Registrando o trabalho realizado em seu grupo, escreveu:

os resultados desses exercicios foram excellentes. Alumnos que, a principio apresentavam posiçãoincorreta e andar desgracioso, corrigiram-se em pouco tempo.

Posição incorreta e andar desgracioso não combinavam com cidadãos republicanos.

A ortopedia que a ginástica realizaria nesses corpos empenados seria conseguida por meio dos exercícios incluídos no programa: marchas militares, exercícios calistênicos e séries de exercícios baseadas no método sueco de ginástica. Com eles, visava-se a "aquisição do poder e do sentido de uma boa atitude normal". Crianças dispostas por filas e colunas, como que em "ordem unida". Não havia prescrição de práticas que envolvessem coletivamente as criancas - o destino dos exercícios era localizado e centrado no sujeito individual. Depois de executar as séries de exercícios, as crianças podiam "brincar livremente pelo pateo, sob supervisão do instrutor".

A adoção do método sueco de ginástica - com esses exercícios físicos individualizados, sistematizados, lineares, regulados, repetitivos, segmentados para cada parte do corpo - fortalece o caráter de ortopedia atribuído à ginástica. Os torpes e tristes corpos infantis precisavam ser restaurados, regenerados, modificados, lapidados, endireitados, higienizados e robustecidos, inscrevendo-se neles os atributos que podiam fazê-los belos, fortes e saudáveis, exigência do novo tempo, da nova civilização. Operar a transmutação de corpos grotescos em corpos, era a contribuição esperada da ginástica.

Naquela pesquisa, indiquei, também, que esse primado orientador da ginástica poderia ser identificado em sua articulação com os processos de organização do trabalho. Representações sobre

6 Arquivo Público Mineiro. Secretaria do Interior, Relatórios dos Grupos Escolares, SI 3597, 1916. Grifo do documento.

7 Cf. MARINHO, s.d./, p. 180.

Movimento, Porto Alegre, v. 10, n. 3, p.77-97, setembro/dezembro de 2004 
a necessidade de preparar crianças para o trabalho circularam fortemente naquele momento, tanto nos ordenamentos legais como nos relatórios de secretários, inspetores e diretoras, influenciando sobremaneira o conjunto das práticas escolares. De fato, o movimento de conformação de um novo molde escolar em Minas Gerais deu-se em torno do trinômio "instruir, educar e dar uma profissão". A inclusão de Trabalhos Manuais já no programa de Ensino Primário da reforma promovida em 1906 que instituiu os Grupos Escolares é um exemplo significativo. ${ }^{8}$ E aqui é preciso perceber e destacar a aproximação produzida nos ordenamentos legais entre os Trabalhos Manuais e a ginástica como dispositivos de "educação physica" das crianças, vinculando-as estreitamente à idéia de envolver os corpos na dinâmica do trabalho.

No âmbito específico da ginástica, é possível perceber vestígios dessa articulação em dispositivos que conformaram seu ensino. Assim, por meio das marchas e das séries de exercícios físicos prescritas, o corpo das crianças era submetido a uma nova organização de tempo (o tempo fracionado, o padrão fixo do tempo, o ritmo, a regularidade, as repetições, as pausas); de espaço (alinhamentos, separações); de ordem (respeito, disciplina); era submetido também aos imperativos econômicos da higiene, para fazer nascer nas crianças uma outra sensibilidade corporal, capaz de produzir uma atitude corporal correta. Estaria aí uma modelagem mais sutil da infância, pretendida com as inserção da ginástica nas práticas dos Grupos Escolares, em seus primeiros momentos, relacionada às novas exigências do trabalho industrial e da vida urbana.

Fundamentalmente, ficou bastante evidente que da presença da ginástica na escola esperava-se essa intervenção ortopédica nos corpos de crianças levados a freqüentar os Grupos Escolares - provenientes de extratos socialmente empobrecidos. Desempená-los e colocá-los em "posição erecta e varonil" era exigência de um desejado novo tempo, de um nova civilização: da escola esperava-se que realizasse a façanha de operar a transmutação de corpos grotescos em corpos refinados, com a contribuição da ginástica.

8 Outro exemplo foi a determinação legal de que "os alumnos que mais se distinguirem nos cursos primarios do Estado, pela intelligencia, bom procedimento e assidua applicacãa" seriam "admittidos gratutitamente nos institutos profissionais, e assidua applicação" seriam "admittidos gratutitamente nos insticutos profissionais, agricolas etc., até o número de 20", sendo que o governo ainda poderia promover "a educação profissional, dentro ou fóra do Estado" de alunos pobres que revelassem "decidida aptidão para as artes mechanicas ou mesmo para as bellas 9 Cf. BARBOSA, 1882.

Movimento, Porto Alegre, v. 10, n. 3, p.77-97, setembro/dezembro de 2004 


\section{Reconfiguração do primado orientador da Gymnastica na década de 1920: em nomeda eficiência}

Ao concluir a Tese, apresentei indicações preliminares de que a década de 1920 parece ter produzido novas exigências para a ginástica na escola, levando-a a uma reconfiguração de seu primado orientador. Agora, retomando esse argumento antes apenas esboçado, tomarei como referência de análise o que se passou em Minas Gerais, destacando a reforma no ensino primário realizada em 1927, que incorporava preceitos do movimento denominado Escola Nova. ${ }^{10}$ Nessa discussão, uma fonte privilegiada aqui será a Revista do Ensino, publicada pelo governo do Estado desde 1925.

É importante assinalar que, em Minas Gerais, é nesta década que o nome "Educação Física" vai se impondo cada vez mais, e definitivamente desde então, para designar essa prática prescrita nos programas escolares.

Tentarei mostrar a seguir que a ginástica ("Educação Física"), se até a década de 20 vinha sendo orientada pelo primado da correção, do endireitamento e da constituição dos corpos, a partir de então, rearticulou-se internamente para atender às demandas da "vida moderna". Isso, todavia, não se deu apenas com a ginástica.

Após a Primeira Guerra Mundial, a pedagogia, pondera Marta Carvalho," "deixava-se impregnar pelos novos ritmos da sociedade e do maquinismo", apostando no "poder disciplinador do progresso", produtor de novas sensibilidades. As circunstâncias abrem um campo fértil para a disseminação de uma pedagogia moderna, alicerçada nos pressupostos da Escola Nova. Nesse movimento, a infância tornase objeto de uma intervenção disciplinar inédita, indica a pesquisadora: "eficiência era o novo nome da disciplina", acentuando que o "otimismo pedagógico" contava não apenas com a "plasticidade da natureza infantil" mas principalmente com "o poder disciplinador das novas exigências postas nos novos ritmos que a técnica e a máquina imprimem à sociedade."12

10 Aqui é importante registrar o trabalho de Omar Schneider, também apoiado em estudos de Marta Carvalho, que aponta para "mutações no significado" de Educação Física nas décadas de 1930 e 1940, que detectou em seu estudo sobre a Revista Educação Physica. Cf. SCHNEIDER, 2004.

11 Cf. CARVALHO, 1997a.

12 Cf. CARVALHO, 1997a. Para a década de 20, a autora propõe que a intervenção pedagógica dá-se não mais pela metáfora da ortopedia, e sim pela metáfora da eficiência.

Movimento, Porto Alegre, v. 10, n. 3, p.77-97, setembro/dezembro de 2004 
A ginástica não ficaria indiferente e alheia a essas "novas exigências". Para atendê-las, rearticulou-se: de uma preocupação antes posta na correção e no endireitamento de corpos, agora seu primado orientador deslocava-se para neles produzir eficiência - moldar corpos eficientes era a nova esperança depositada na ginástica.

Como então registrei, o enunciado regulador desse novo primado pode ser encontrado e sintetizado nas instruções ao professorado mineiro contidas na reforma do ensino primário de 1927, que adota pressupostos da Escola Nova: "A educação physica traz benefícios, não só de ordem individual, como também de ordem social e nacional."

Observe-se que o texto reformista traduzia uma desejada repercussão do ensino de Educação Física muito além do que poderia fazer por um aluno em particular: ela deveria produzir impactos no plano da organização nacional. Assim, se para a "educação do corpo, a gymnastica é, sem dúvida, o agente poderoso" que o torna "sadio, bello e forte", sua presença na escola era defendida também porque atuaria nas crianças "sugerindo ao espirito força de vontade, energia, coragem, decisão, alegria e cordialidade." O corpo é aí representado como guardião e condutor de um "espirito" altivo que o habitaria, impregnado dos valores considerados fundamentais para a causa nacional do desenvolvimento do país.

O referido deslocamento evidenciava-se: mais que corrigir e endireitar corpos, a ginástica foi convocada a introjetar nas crianças não apenas uma atitude corporal correta, mas uma atitude corporal eficiente. Dela esperava-se que pudesse produzir uma nova sensibilidade corporal nas crianças. O trabalhador necessário à indústria deveria ser dotado não somente de corpos "erectos", mas sobretudo de corpos eficientes, impregnados de "espirito coletivo", prontos para o trabalho em conjunto que, de maneira eficaz, tivesse rendimento em forma de produto, de resultado. A idéia de incutir hábitos de trabalho nas crianças, propugnada por entusiastas da educação, parece ter encontrado na ginástica um campo fértil para deitar raízes.

Este deslocamento em seu primado regulador inauguraria um novo momento para a história escolar da Gymnastica ("Educação Física") em Minas Gerais, a partir da década de 20.

Um dos indícios mais fortes dessa reconfiguração — da correção à eficiência dos corpos - , foi a ampliação de seu programa no ensino primário, com a escolarização de novas práticas. Se nas décadas anteriores, o programa esteve, em Minas Gerais, restrito às marchas

Movimento, Porto Alegre, v. 10, n. 3, p.77-97, setembro/dezembro de 2004 
militares e séries de exercícios físicos, sob influência do método sueco de Ginástica, a década de 20 assistiu à escolarização de outras, como a "gymnastica rythmica", os "exercicios naturaes", os "exercicios respiratorios", e os "jogos". Dentre elas, destacarei aqui o movimento de escolarização dos jogos (que, aliás, ocorreu não apenas por intermédio dos programas de ginástica).

Para acompanhar essa reflexão a respeito desse movimento, considerei interessante antecipar e registrar uma observação de Fernando de Azevedo a respeito dos "novos caminhos e novos fins"13 que a educação deveria assumir diante das circunstâncias brasileiras de então, marcadas pela aproximação com as exigências do trabalho, melhor, da "organização do trabalho nacional", como ele próprio defendeu.

Em uma conferência proferida em 21 de novembro de 1929, por iniciativa da Federação Nacional das Sociedades Educativas, com o título "A Socialização da Escola", ao discorrer sobre a "organização interna da escola, de acordo com a nova finalidade social", Azevedo insistiu na "adaptação da escola ao meio imediato", adotando "o princípio da escola-comunidade", defendendo que "a escola deve assumir, de acordo com êsse princípio, feição de uma sociedade em miniatura, em que vivam e trabalhem, como pequenas comunidades, as classes que formam, no seu conjunto, a comunidade maior, - a escola, integrada no quadro social e adaptada às suas exigências, e, portanto, às próprias necessidades dos alunos". Fundamental, para ele, era o "exercício normal do trabalho em cooperação", sobre o qual ponderou que a "escola aparelhada de material e instalações necessárias para o exercício de atividades educativas proporciona os meios para que o trabalho seja o centro da vida escolar, em torno do qual gravitam e se organizam todos os estudos e lições práticas (...). Ao realçar a necessidade destas "atividades em cooperação", ele então comentou:

A educação não deve apenas basear-se nas leis psicológicas elementares do pensamento, da ação e da conduta individuais, mas nas tarefas ideais das sociedades humanas, em vistas das quais os indivíduos têm o dever de formar-se, e às quais as condutas particulares devem subordinar-se e adaptar-se. Ora, as atividades sociais apresentam-se com êsse carater de cooperação, em sociedades cooperativas de produção e de consumo, na formação de classes ou sindicatos e, enfim, na organização científica do trabalho em que 'um interêsse coletivo orienta, harmoniza e disciplina os esforços e interesses individuais, quase sempre

incoerentes, dispersivos e contraditórios'. O trabalho em cooperação, que constitui um dos princípios fundamentais da escola-comunidade, adotada pela reforma

13 Este é o título de sua obra, aqui consultada: Cf. AZEVEDO, 1958.

Movimento, Porto Alegre, v. 10, n. 3, p.77-97, setembro/dezembro de 2004 
do ensino, contribui para a formação do sentido social, do sentido da comunidade, e, para a solução, pela escola, de um dos mais graves problemas postos na organização das sociedades modernas.

E ilustrou sua observação com este exemplo, que assume importância capital para a reflexão aqui desenvolvida:

"É por isso mesmo que em tôda parte se aclimataram tão ràpidamente, pelo próprio instinto social, os jogos por turmas, os esportes baseados sôbre o grupo (os esportes anglo-saxônicos), que acabaram adquirindo, senão o domínio exclusivo, uma predominância acentuada sôbre os esportes individuais, em que, como espírito de iniciativa individual, não se põe em jôgo, nem se exercita a capacidade de cooperação".

Jogos por turmas. Esportes em grupo. Esportes anglo-saxônicos. Exercitar a capacidade de cooperação. É o caso de perguntar: seriam essas práticas escolarizadas "em toda parte" pelo "próprio instinto social"?

\section{Escolarizando jogos para imprimir eficiência aos corpos}

Em Minas Gerais, uma das estratégias mobilizadas para a escolarização de jogos foi a Revista do Ensino. ${ }^{14}$ Criada em 1892 no governo do presidente Affonso Penna, a Revista foi inteiramente reformulada em 1925, na presidência de Fernando Mello Vianna, quando passa a circular mensalmente, sob responsabilidade da Diretoria de Instrucção Publica, "destinada a orientar, estimular e informar os funcionários do ensino e os particulares interessados", como prevê o Regulamento do Ensino (art. 479). ${ }^{15}$ Assim, a Revista do Ensino constituiu suporte fundamental na divulgação da política educacional do governo por todo o Estado de Minas Gerais, como "tentativa de unificação de uma nova organização e administração da rede escolar [...], inspirados na Escola Nova". É então que se pode considerá-la nuclear para a conformação do campo escolar e, particularmente, para a consolidação e reconfiguração da agora

14A Revista do Ensino de Minas Gerais vem sendo objeto de inúmeros trabalhos acadêmicos dentre os quais destaco os de BORGES (1993), SOUZA (2000), BICCAS (2001).

15 A sua estrutura constava de uma "parte doutrinária", cujos objetivos eram "dirigir o professorado publico do Estado, harmonizando seus esforços", "pô-lo ao corrente da evolução do ensino primário em todos os seus aspectos" e "publicar-Ihe os trabalhos ou extratos destes, quando de evidente interesse didático" (art. 480).

Movimento, Porto Alegre, v. 10, n. 3, p.77-97, setembro/dezembro de 2004 
chamada Educação Física, com conseqüências importantes na formação do professorado para realizar seu ensino.

Em outro trabalho, ${ }^{16}$ afirmei ser a Revista do Ensino uma estratégia de formação do professorado mineiro para realizar o ensino de Educação Física. Com efeito, foi grande a circulação de artigos na Revista que direta ou indiretamente se referiam à Educação Física, configurando uma campanha permanente para a sua inserção e consolidação nas práticas escolares, sendo evidente a intenção de conformar a ação pedagógica do professorado.

O Quadro 1, a seguir, traz um levantamento dos seis primeiros anos de circulação da Revista (do Ano 1, 1925, após sua reformulação, ao ano 6, 1930). Em um universo pesquisado de 52 números, ${ }^{17}$ há 39 artigos ou seções destinadas seja à "Educação Physica", explicitamente, seja a seções dedicadas a Jogos, Recreação, Educação Estética, à melhoria da "raça", dentre outros. Representações sobre a Educação Física são postas em circulação, com objetivos defendidos e autorizados para ela, combinando-se com prescrição de práticas indicadas para realização em suas aulas.

A pretensão de fomentar, legitimar e organizar o ensino de Educação Física é evidente, buscando-se para isso incentivar e capacitar o professorado para assumir tal responsabilidade, oferecendo-lhe ao mesmo tempo suporte teórico, recomendações de natureza metodológica e sugestões de atividades. Por isso é que a Revista do Ensino é aqui considerada como suporte importante produzido pelo governo de Minas para a formação do professorado, também no que diz respeito à Educação Física. Tal importância é potencializada sabendo-se que não havia então cursos específicos de formação de professores nesta área. A formação do professorado para

Esta parte devia "limitar-se a publicações de pequenos trabalhos de interesse imediato, resumo de obras e artigos extraidos de revistas congeneres, nacionais ou extrangeiras" (art. 481). Além desta, havia também a previsão de uma "parte noticiosa", destinada a publicar "factos e ocorrências locais, nacionais ou noticiosa", destinada a pubientar " funcionários do ensino", ácm de "dac ou extrangeiras, que possam orientar os funcionários do ensino", além de "dados estatísticos relativos á instrucção" e de "actos oficiais que interessem aos funcionários do ensino conhecer" (art. 480). A Revista do Ensino transformou-s num "órgão público de divulgação, orientação e fiscalização das medidas pública tomadas pelo Estado de Minas", na área da instrução. Nela passam a ser publicados, além de artigos sobre as diversas cadeiras do programa de ensino, leis, decretos e atos oficiais, dados estatísticos sobre freqüência escolar e expansão do atendimento e, ainda, textos traduzidos de literatura estrangeira, especialmente francesa e americana, acerca da Pedagogia Escolanovista. 16 Cf. VAGO, 1999

17 Os números 16 e 17 saíram em uma mesma edição, o que se repete com os números 50, 51 e 52 .

Movimento, Porto Alegre, v. 10, n. 3, p.77-97, setembro/dezembro de 2004 
ministrá-la estava restrita às Escolas Normais então existentes. ${ }^{18} \mathrm{Com}$ a reforma do ensino primário de 1927, ela é também mobilizada para difundir princípios e orientações, publicando-se nela toda a legislação pertinente, as resoluções de governo, os programas do ensino primário, enfim, com vistas a dar-lhe ampla divulgação.

Para o propósito deste trabalho, o realce recairá, como indicado, à intensa circulação na Revista de artigos prescrevendo jogos, sendo fundamental indagar os sentidos com que eles foram largamente autorizados e incentivados nas escolas e o impacto que a escolarização desta prática tem para a Educação Física.

18Cf. VAGO, 1997, 1999. A primeira iniciativa de formação específica do professorado em Educação Física em Minas Gerais foi a criação do "Curso Intensivo de Educação Física", promovido pela Inspetoria de Educação Física. Esta Inspetoria foi criada com o Decreto n. 7.970-A, de 15 de outubro de 1927, assinado pelo Presidente Antônio Carlos e por seu Secretário do Interior Francisco Campos, após o I Congresso de Instrucção Primária de Minter Congresso de Instrucção Primária de Minas Gerais (maio de 1927), e apenas um mês antes da reforma do ensino primário. Já neste Decreto que a institui prevê-se como uma de suas atribuições "ministrar na Capital um curso especial para formação e aperfeiçoamento do pessoal docente destinado ao ensino de educação physica" (art. 94)

Movimento, Porto Alegre, v. 10, n. 3, p.77-97, setembro/dezembro de 2004 
Quadro 1. Artigos e Seções da Revista do Ensino dedicados à Educação Física e aos Jogos

\begin{tabular}{|c|c|c|c|}
\hline ANO & NÚMERO & MÊS & ARTIGOS / SEÇÕES \\
\hline \multirow{7}{*}{$\begin{array}{l}1925 \\
\text { Ano } 1\end{array}$} & 3 & Maio & Jogos Menores [13 jogos] \\
\hline & 4 & Junho & Gymnastica Respiratória \\
\hline & 5 & Julho & $\begin{array}{l}\text { Secção Recreativa: Jogos Physicos na Escola [ } 30 \\
\text { jogos] }\end{array}$ \\
\hline & 6 & Agosto & Secção Recreativa: Jogos Menores [13 jogos] \\
\hline & 7 & Setembro & $\begin{array}{l}\text { Educação Esthetica } \\
\text { Technica sobre Educação Physica } \\
\text { Gymnastica } \\
\text { Secção Recreativa: Jogos Menores [ } 14 \text { jogos] }\end{array}$ \\
\hline & 8 & Outubro & Secção Recreativa: Jogos Activos [18 jogos] \\
\hline & 9 & Dezembro & $\begin{array}{l}\text { Para Dar um Fremito de Vida ao Ambiente } \\
\text { Escolar: Descripção de Alguns Jogos Interessantes } \\
\text { [13 jogos] }\end{array}$ \\
\hline \multirow{8}{*}{$\begin{array}{l}1926 \\
\text { Ano } 2\end{array}$} & 10 & Janeiro & $\begin{array}{l}\text { Para fazer a raça forte e energica: Methodos de } \\
\text { Educação Physica }\end{array}$ \\
\hline & 11 & Fevereiro & Methodos de Educação Physica \\
\hline & 12 & Março & $\begin{array}{l}\text { Jogos nas Escolas: Horas de Alegria e de Força } \\
\text { Para fazer a raça forte e enérgica }\end{array}$ \\
\hline & 13 & Abril & $\begin{array}{l}\text { O Encanto do Recreio nas Escolas } \\
\text { Noções de Educação Physica: Exercicios e Jogos }\end{array}$ \\
\hline & 14 & Maio & Noções de Educação Physica \\
\hline & 15 & Junho & A Alegria dos Recreios: Diversos Jogos Gymnasticos \\
\hline & $16 / 17$ & $\begin{array}{l}\text { Julho } \\
\text { Agosto }\end{array}$ & Educação Physica Pela Beleza da Raça \\
\hline & 19 & Dezembro & Educação Physica \\
\hline \multirow{4}{*}{$\begin{array}{l}1927 \\
\text { Ano } 3\end{array}$} & 20 & Abril & $\begin{array}{l}\text { A GRD [Ginástica Rítmica Desportiva] na Opinião de } \\
\text { um Especialista }\end{array}$ \\
\hline & 22 & $\begin{array}{l}\text { Agosto } \\
\text { Setembro }\end{array}$ & $\begin{array}{l}\text { Theses do Congresso de Instrucção Primaria sobre a } \\
\text { hygiene e educação physica }\end{array}$ \\
\hline & 23 & Outubro & O medico educador \\
\hline & 24 & Novembro & O medico educador \\
\hline
\end{tabular}

Movimento, Porto Alegre, v. 10, n. 3, p.77-97, setembro/dezembro de 2004 


\begin{tabular}{|c|c|c|c|}
\hline ANO & NÚMERO & MÊS & ARTIGOS / SEÇÕES \\
\hline \multirow{3}{*}{$\begin{array}{l}1928 \\
\text { Ano } 4\end{array}$} & 26 & Outubro & $\begin{array}{l}\text { Educação Physica } \\
\text { Gymnastica }\end{array}$ \\
\hline & 27 & Novembro & $\begin{array}{l}\text { Pequenos Jogos } \\
\text { Nomenclatura de Calistenia }\end{array}$ \\
\hline & 28 & Dezembro & Educação Physica: marchas \\
\hline \multirow{5}{*}{$\begin{array}{l}1929 \\
\text { Ano } 5\end{array}$} & 29 & Janeiro & Educação Physica: Jogos Gymnasticos \\
\hline & 33 & Maio & Educação Physica: Jogos Menores, Jogos Athleticos \\
\hline & 34 & Junho & $\begin{array}{l}\text { Educação Esthetica da Infância } \\
\text { A Educação Physica }\end{array}$ \\
\hline & 35 & Julho & A Educação Physica Moderna \\
\hline & 37 & Setembro & O jogo, a imitação e o interesse como factores da educação \\
\hline \multirow{3}{*}{$\begin{array}{l}1930 \\
\text { Ano } 6\end{array}$} & 47 & Julho & $\begin{array}{l}\text { Qual parte que deve caber à Educação Physica na ensino } \\
\text { primário? }\end{array}$ \\
\hline & 49 & Setembro & $\begin{array}{l}\text { Praticabilidade de uma Gymnastica Electiva nos grupos } \\
\text { escolares }\end{array}$ \\
\hline & $50 / 51 / 52$ & $\begin{array}{l}\text { Outubro } \\
\text { Novembro } \\
\text { Dezembro }\end{array}$ & Estado Physico das creanças \\
\hline
\end{tabular}

Fonte: Revista do Ensino, MG, n. 1 (1925) a n. 52 (dezembro, 1930)

No Quadro l é possível perceber o movimento de escolarização de jogos por meio da Revista. Levantamento preliminar mostrou que em cinco anos ultrapassou de 100 o número de recomendações e indicações de jogos, muitos acompanhados de desenhos explicativos e de frases em si mesmas significativas, assim como já bastante expressivos também são os nomes das seções da Revista em que se publicavam as suas descrições, traduzindo as pretensões a eles dedicados: "Secção Recreativa: Jogos Activos"; "Para Dar um Fremito de Vida ao Ambiente Escolar: Descripção de Alguns Jogos Interessantes": "Jogos nas Escolas: Horas de Alegria e de Força"; "O Encanto do Recreio nas Escolas"; "Noções de Educação Physica: Exercicios e Jogos"; "A Alegria dos Recreios: Diversos Jogos Gymnasticos".

A "Secção Recreativa" teve presença marcante no primeiro ano de circulação da Revista, 1925, aparecendo quatro vezes. Em seu número 5, de julho de 1925, ela trouxe como tema "Jogos Physicos nas Escolas", publicando "jogos menores e corridas", organizados

Movimento, Porto Alegre, v. 10, n. 3, p.77-97, setembro/dezembro de 2004 
(ou mesmo inventados) pela professora D. Maria Bueno, da cidade mineira de Lavras. Novamente no número $7,{ }^{19}$ a "Secção Recreativa" também versou sobre "Jogos Menores", prescritos, a propósito, na Reforma do Ensino Normal de $1925 .^{20}$ Aliás, alguns jogos citados no artigo são exatamente os mesmos lá indicados: pega-pega avestruz e roubar munições, por exemplo. Além desses dois, outros treze jogos são recomendados ao professorado para ensinar às crianças: pegar a corda; batalha; passar a bola a cavallo; barra; o veado quer fugir, corrida de círculo; luta montado; tomar a trincheira; empurrar a corda; ida e volta; pega-pega indú; pega-pega montado e boia cortada. Já no mês seguinte, com o número $8,{ }^{21}$ a "Secção Recreativa" foi dedicada aos "Jogos Activos", e mais 17 jogos são indicados: barra; flores ao vento; corrida contraria; pegador, o esquilo; muralha chinesa; jogo chinez; o gato e orato; viuva; ogatoem seu cantinho; gato doente; chicote queimado; trem deferro; caminho a Jerusalem; pega-pega contrario; Dooge Ball; saccos de feijão.

"Os jogos nas Escolas - Horas de Alegria e de Força", era outra seção da Revista. ${ }^{23}$ Interessante notar a representação produzida em torno dos jogos: eles combinariam dois objetivos: produzir "alegria" nas crianças, mas também desenvolver nelas a "força". Percebe-se aí que se a adoção dos princípios escolanovistas estava em andamento em Minas, nem por isso a escola abandonava o primado anterior, de constituição dos corpos de crianças, de que a ginástica era expressão. Esta seção traz no número de março de 1926 uma contundente evidência da tentativa de imposição de um modelo de corporeidade a ser seguida:

A cultura physica aperfeiçoa e embelleza o corpo humano. Haja vista a superioridade aristocratica do typo inglez. Na Inglaterra, os jogos escolares éque constituem a gymnastica da mocidade escolar."

Miragem estética, o "typo ingles" é o modelo de perfeição e beleza a ser seguido, com sua dita "superioridade aristocratica". E o fato de os jogos serem, segundo a Revista, o conteúdo da "gymnastica da mocidade escolar" da Inglaterra, contribui para explicar a insistente indicação dessas práticas em sucessivas seções, sendo que os nomes sequer foram traduzidos: deck tennis, center cath ball, por exemplo. E,

19 REVISTA DO ENSINO, Belo Horizonte, MG, Ano I, 1925 (setembro), n. 7, p. 197198.

20 MINAS GERAIS, Decreto n. 6.831, de 20 de março de 1925.

21 REVISTA DO ENSINO, Belo Horizonte, MG, Ano I, 1925 (outubro), n. 8, p. 237-240.

22 Após a descrição deste jogo, há a seguinte observação: "Este jogo se acha em toda a parte - Japão, Italia, etc. É um dos mais antigos". A Revista contribuía para a escolarização de práticas (jogos, no caso), produzidas fora dela.

23 REVISTA DO ENSINO, Belo Horizonte, MG, Ano II, 1926 (março), n. 12, p. 94-97

Movimento, Porto Alegre, v. 10, n. 3, p.77-97, setembro/dezembro de 2004 
então, a Revista defende uma premissa que é recorrente nas seções dedicadas aos jogos: "as crianças, que se dedicarem aos jogos, terão superioridade, quer physica, quer moral, sobre os companheiros que tenham desprezado essa disciplina."

A Revista pretendia convencer o professorado mineiro a ensinar jogos e ao mesmo tempo lhe oferece um argumento para seduzir os alunos para a sua prática: a "superioridade physica e moral" sobre os que ousassem desprezá-los. Esse argumento será reproduzido em outros números do periódico.

Ora, tomar o que se fazia em escolas da Inglaterra como inspiração é algo por demais emblemático. Aqui, é preciso tomar em consideração, ainda que brevemente, o movimento de escolarização de jogos populares em escolas inglesas, a partir do século XVIII. Nessas escolas, a regulamentação e a racionalização desses jogos teria produzido o aparecimento do esporte na modernidade, sob o impacto dos processos de urbanização e industrialização, que os marcam profundamente - o esporte é uma invenção moderna, e não por acaso foi na Inglaterra que ocorreram seus primeiros desenvolvimentos, expandindo-se paulatinamente para fora dela.

Não foi também por acaso que Fernando de Azevedo referiuse aos "esportes anglo-saxônicos" como possibilidade de "trabalho em cooperação", o que teria feito com que se "aclimatassem" rapidamente em toda parte. E ele o diz justamente no momento em que se defendia a aproximação entre escola e trabalho, acompanhado de tantos entusiastas da educação. O que faria jogos e esportes desejáveis na escola? A resposta de Azevedo - o trabalho em cooperação - é um indício que merece ser explorado (e por isso o retomarei adiante).

Outra resposta vem das necessidades da própria escola, e encontra-se no título em si mesmo revelador de outra seção da Revista do Ensino: "Para dar um fremito de vida ao ambiente escolar". Em seu número $9{ }^{24}$ por exemplo foi publicada a "descripção de alguns jogos interessantes", como o Deck Tennis; Grãos de Feijão; Corrida em carteiras; Jogo de balões; Bom dia; Zig-zig; Reinos da Natureza; Relay; Estatua; Center Stride Ball; Center Cath Ball; Jacob e Rachel; Jogos quietos. O nome de alguns jogos mais uma vez reforçam a influência inglesa em sua seleção. Países considerados civilizados tornavam-se referência da "vida moderna" que se almejava, com o concurso da escola.

24REVISTA DO ENSINO, Belo Horizonte, MG, Ano I, 1925 (dezembro), n. 9, p. 269-270.

Movimento, Porto Alegre, v. 10, n. 3, p.77-97, setembro/dezembro de 2004 
São exemplos de que o jogo vai se tornando um tema privilegiado em seções ou artigos da Revista, recomendado para ser incluído no programa de Educação Física. E muitas vezes aparece atrelado à ginástica - o chamado "jogo gymnastico" sendo assim considerado "a mais natural forma de exercicio". A aliança entre essas duas práticas corporais é então defendida:

Nos jogos gymnasticos, cuja orientação vamos dando, a criança vê, não uma disciplina escolar, porém uma derivação de prazer dentro de suas obrigações diuturnas, de valor extraordinário como exercicio physico.

É uma tentativa de juntar prazer e obrigação: jogo e ginástica. Tentativa que ficará ainda mais explícita poucos meses depois, no número 19 da Revista ${ }^{25}$ (dezembro de 1926):

Aos exercicios de gymnastica, uniformes, faltam a emulação, oattractivo, ointeresse que os jogos infantis despertam. E a criança entregue a essa disciplina sente-se feliz, demonstrando intelligencia precoce em suas attitudes.

Tomarei para exemplo um jogo prescrito neste mesmo artigo da Revista. Curioso é que ele não têm suas origens na escola, nem parece ser importado de países tidos como civilizados: "Entre os jogos gymnasticos de grande effeito sobre o organismo, está o da petéca já conhecido das crianças".

Observe-se: há o reconhecimento de que a peteca é já uma prática conhecida das crianças. Em que lugar elas praticavam a peteca? Nos quintais e nas varandas das casas? Nas ruas e praças das cidades? É improvável que em suas origens indígenas ${ }^{26}$ a peteca tenha sido praticada com a preocupação de produzir "grande effeito sobre o organismo". Assim também nas ruas, praças, varandas e nos quintais. Seu significado, nesses lugares, parece mais próximo de um divertimento, de uma brincadeira. Mas, o artigo da Revista, ao promover sua escolarização, começa já por lhe dar a classificação de "jogo gymnastico". Ao fazê-lo, aproveita o seu sentido de divertimento (como jogo) ao mesmo tempo em que imputa-lhe a seriedade pretendida (como ginástica), justamente para que possa realizar o que dela se esperava, na escola: produzir efeitos sobre o organismo. A peteca é submetida a uma metamorfose em sua inserção na escola.

25 REVISTA DO ENSINO, Belo Horizonte, MG, Ano II, 1926 (dezembro), n. 19, p. 387-389 26 "Em relação à peteca, alguns especialistas apontam a origem estritamente brasileira, proveniente de tribos tupis do Brasil e que se expandem em regiôes densamente populadas pelos indígenas, como Minas Gerais. (...). (em tupi, 'bater' é 'peteca', populadas pelos indígenas, como Minas Gerais.
em guarani é 'petez')." (Cf. KISCHIMOTO, 1993)

Movimento, Porto Alegre, v. 10, n. 3, p.77-97, setembro/dezembro de 2004 
E a escolarização da peteca não se encerra aí: "Para que este jogo produza seus efeitos beneficos, torna-se necessario que o professor procure regulamental-o". O artigo indica que a peteca deve ser de couro, tendo 7 a 8 centímetros na base.

A escola, por um de seus agentes (o professor) vai então regulamentar a prática da peteca, segundo valores que ela defende, com os objetivos que lhe interessam. E não só vai regulamentar o agora chamado jogo ginástico da peteca, como também vai criar variações para a sua prática. Como, por exemplo, a publicada no mesmo artigo, em que o professor se coloca no centro de um círculo formado pelos alunos, remete a peteca a um deles que deverá devolvê-la imediatamente. Mas, "si a deixar cahir, o alumno sahirá do jogo, continuando o professor em actividade com os demais (...). Os ultimos jogadores serão os vencedores". No lugar do professor, poderá ocupar o centro "o alumno mais agil". Assim, o que era uma prática de divertimento agora é transformada em um jogo de competição, onde a exclusão é a regra principal, porque pretende-se chegar aos vencedores - os mais ágeis, os melhores.

Então, também neste artigo reafirma-se, como se fosse um mantra, que "as crianças que se dedicarem aos jogos terão superioridade quer physica, quer moral sobre os companheiros que tenham desprezado essa disciplina".

Escrever isso em uma Revista autorizada e mantida pelo Governo, de circulação estadual, foi com efeito uma contundente estratégia de escolarização de jogos, potencializada com o apelo à "superioridade" de seus praticantes. A Revista configura-se também como dispositivo de formação do professorado, ao prescrever-lhes práticas que pretendiam conformar seu ensino.

\section{Considerações finais}

Com os exemplos tratados, é importante agora, para concluir, deter-se um pouco mais sobre esse movimento de escolarização dos jogos, com forte impacto na Educação Física.

A reforma de 1927 (e antes dela a própria Revista do Ensino) encontrou na Educação Física campo privilegiado para realizar este movimento (embora a escolarização de jogos não se restrinja aos tempos da Educação Física). É então que tornou-se evidente a reconfiguração de seu primado orientador, da correção para a eficiência dos corpos. Vejamos.

Movimento, Porto Alegre, v. 10, n. 3, p.77-97, setembro/dezembro de 2004 
Dos jogos esperava-se algo que eles poderiam proporcionar, que ultrapassa (sem desprezar) o princípio de correção dos corpos. A escolarização dos jogos parece indicar uma mudança no foco de atenção, que desloca-se do sujeito individual para o sujeito coletivo. Eles oferecem uma oportunidade impossível nas marchas e séries de exercícios físicos até então prescritas: é a capacidade de proporcionar a "experiência coletiva", o "trabalho em cooperação", como preconizou por exemplo Fernando de Azevedo. Eles teriam o pendão de atrair e mobilizar coletivamente as crianças na consecução de um fim, de um resultado: nos jogos deve-se atingir a uma finalidade, e para isso são regulados por regras, que devem ser aprendidas, incorporadas - tornadas corpo - , respeitadas e praticadas. Ou seja: depois de uma disputa, de uma competição, há uma conquista, uma vitória, um resultado, o que exige empenho, esforço, dedicação, rendimento ou, como no texto da reforma do ensino primário de 1927, destreza, habilidade, agilidade, observação, e "espirito de colletividade".

Percebe-se que esse "espirito de colletividade", essa socialização, essa cooperação que os jogos promoveriam na escola são marcados não por uma solidariedade pela solidariedade. É uma socialização marcada pela eficiência. Eficiência que produz um resultado. Não era mais suficiente que corpos de crianças vale dizer: crianças filhas de trabalhadores, cujo destino social para elas previsto era o trabalho em suas novas configurações na indústria —, fossem apenas 'desentortados', 'desempenados', enfim, corrigidos em sua postura para atingir uma atitude corporal correta. Uma nova necessidade se afigurava: era preciso que se tornassem portadores de atributos indispensáveis à inserção nas complexas relações sociais de trabalho, em que eficiência, rendimento e resultado tornavam-se exigências que credenciavam (ou marginalizavam) trabalhadores. Corpos de crianças - potenciais trabalhadoras - deveriam ser dotados de uma atitude corporal eficiente.

Pois não é essa - a eficiência - uma marca que traduz a "vida moderna" tanto almejada para o País na década de 1920? Em meu entendimento, encontra-se aí uma chave para entender a inserção de jogos (e também do esporte) nos programas escolares, e para compreender os impactos disso na Educação Física.

Ela tornou-se centralmente responsável por sua escolarização, do que resultou a produção e a circulação de novas representações sobre seu lugar nas práticas escolares, e novas maneiras de organizar seu ensino foram conformadas. Imprimir eficiência

Movimento, Porto Alegre, v. 10, n. 3, p.77-97, setembro/dezembro de 2004 
aos gestos, aos movimentos corporais das crianças - aos seus corpos. Essa, a nova exigência posta para a Educação Física dando sentido novo à sua presença nos programas escolares.

Resta evidente que o movimento de escolarização dos jogos, que indicia o deslocamento da Educação Física do primado da correção para o primado da eficiência dos corpos, não parece produto do "próprio instinto social", como propôs Fernando de Azevedo, mas do que ele mesmo proclamou como necessidade: de a escola basear-se "nas tarefas ideais das sociedades humanas, em vistas das quais os indivíduos têm o dever de formar-se, e às quais as condutas particulares devem subordinar-se e adaptar-se."

Parece-me que foi dessa "socialização da escola" que Fernando de Azevedo tratou em sua conferência de 1929, ecoando o otimismo que se depositava na educação como recurso para a "organização do trabalho nacional", citando os jogos e os esportes como exemplo.

Ao se deslocar da ortopedia à eficiência, a Educação Física refinava sua sintonia com a "vida moderna".

De la ortopedia a la eficiencia de los cuerpos:
La Gymanasia y las exigencias de la vida moderna
(Minas Gerais, 1906-1930)
Resumen: El artículo trata de la inserción de la gimnasia
(Educación Física) en los programas de enseñanza prima-
ria en Minas Gerais, en las tres primeras décadas del siglo
XX, discutiendo representaciones que conformaron su
enseñanza. En este periodo, habría ocurrido una
reconfiguración en su primado orientador: si inicialmente
la gimnasia fue orientada como práctica ortopédica de
corrección de los cuerpos de los niños, la década de 1920
parece traer nuevas exigencias para ella, articuladas a las
necesidades de organización del trabajo. Es desde entonces
que el primado de la eficiencia se impone como orientador
de su enseñanza. De la ortopediaa la eficiencia, la Educación
Física refinaba su sintonía con la "vida moderna".
Palabras-clave: Gimnasia, Educación Física, Escuela,
Cuerpo, Historia de la Educación Física.

Movimento, Porto Alegre, v. 10, n. 3, p.77-97, setembro/dezembro de 2004 


\section{From orthopedy to the efficiency of the bodies:} Gymnastics and the demands of "modern life" (Minas Gerais, 1906-1930)

Abstract: This article addresses the insertion of gymanastics (physical education) in preschool programs, in Minas Gerais during the three first decades of the $20^{\text {th }}$ century, discussing the representations of such subject. During such time, there would have been a reconfiguration of its leading factor: whether or not gymnastics was seen as orthopedics practices of children's physical correction, the 1920 s seems to have imposed new demands to it related to the necessity of organizing the teaching practices. It is, then, that efficiency poses itself as the driving force of such subject. From orthopedics to efficiency, physical education would come in synch with modern life.

Keywords: Gymnastics, Physical Education, School, Body, Physical Education History.

\section{Referências}

BICCAS, Maurilane de Souza. O impresso como estratégia de formação de professores(as) e de conformação do campo escolar em Minas Gerais: o caso da Revista do Ensino (1925-1940). Tese, FE/USP, São Paulo, 2001.

BORGES, Vera Lúcia Abrão. A ideologia do caráter nacional da educação em Minas - Revista do Ensino (1925 - 1929). Campinas: Unicamp, Faculdade de Educação (Dissertação, Mestrado em Educação), 1993. 108p.

CARVALHO, Marta M. Chagas. \& NUNES, Clarice. Historiografia da educação e fontes. Cadernos Anped, n. 5, Porto Alegre (RS), p. 7-64, set., 1993.

Quando a história da educação é a história da disciplina e da higienização das pessoas. In: FREITAS, Marcos Cezar (Org.). História social da infância no Brasil. São Paulo: Cortez, 1997.

Educação popular e reformas da instrução pública no Brasil na década de 1920, s./d. (digit).

História da Educação: notas sobre uma questão de fronteiras. Educação em Revista. Belo Horizonte: Autêntica/Faculdade de Educação da UFMG, n. 26, dez., 1997b, p. 5-15.

Por uma história cultural dos saberes escolares. In: II CONGRESSO LUSO-BRASILEIRO DE HISTÓRIA DA EDUCAÇÃO. USP, Faculdade de Educação, fev. 1998.

CERTEAU, Michel de. A invenção do cotidiano - Artes de fazer. Petrópolis: Vozes, 1994.

A escrita da história. Rio de Janeiro: Forense-Universitária, 1982. A cultura no plural. Campinas: Papirus, 1995.

Movimento, Porto Alegre, v. 10, n. 3, p.77-97, setembro/dezembro de 2004 
CHARTIER, Roger A história cultural - Entre práticas e representações. Lisboa: Difel, 1990.

O mundo como representação. Estudos Avançados. São Paulo: Instituto de Estudos Avançados, USP, v. 5, n. 11, jan/abr., 1991.

A história hoje: dúvidas, desafios, propostas. Estudos Históricos, Rio de Janeiro, CPDOC, v. 7, n. 13, p. 97-114, 1994

CHERVEL, André. História das disciplinas escolares. Teoria \& Educação. Porto Alegre, n. 2, p. 177-229, 1990.

ESCOLANO, Augustín. Arquitetura como programa: espaço-escola e currículo. In: ESCOLANO, Augustín \& VINÃO FRAGO, Antonio. Currículo, espaço e subjetividade: a arquitetura como programa. Trad. Alfredo Veiga-Neto. Rio de Janeiro: DP\&A, 1998.

FARIA FILHO, Luciano Mendes de. Conhecimento e cultura na escola: uma abordagem histórica. In: DAYRELL, Juarez (Org.). Múltiplos olhares sobre educação e cultura. Belo Horizonte: Ed. da UFMG, 1995a.

Cultura e práticas escolares: escrita, aluno e corporeidade. Cadernos de Pesquisa, Fundação Carlos Chagas, n. 103, p. 136-149, mar. 1998.

. Dos pardieiros aos palácios; forma e cultura escolares em Belo Horizonte (1906-1918). São Paulo: USP (Tese, doutorado em Educação), Faculdade de Educação, 1996.

A história da educação e os desafios das novas fontes: reflexões sobre uma trajetória de pesquisa, 1997 (digit).

FOURQUIN, Jean-Claude. Escola e cultura: as bases sociais e epistemológicas do conhecimeno escolar; trad. Guacira Lopes Louro. Porto Alegre: Artes Médicas, 1993.

MINAS GERAIS. Coleção de Leis e Decretos do Estado de Minas Gerais. Imprensa Oficial; 1892-1930.

Secretaria de Estado dos Negócios do Interior. Relatórios do Secretário ao Presidente do Estado, 1898-1918.

NÓVOA, Antonio. Inovação e história da educação. Teoria \& Educação. Porto Alegre, n. 6, p. 210-220, 1992.

NUNES, Clarice. História da educação brasileira: novas abordagens de velhos problemas. Teoria \& Educação. Porto Alegre, n. 6, p. 151-182, 1992.

SCNEIDER, Omar. Entre a correção e a eficiência: mutações no significado da educação física nas décadas de 1930 e 1040 - um estudo a partir da revista Educação Physica. In: Revista Brasileira de Ciências do Esporte. Campinas, Colégio Brasileiro de Ciências do Esporte, v. 25, n. 2, p. 39-54.

SCHWARCZ, Lilia Moritz. O espetáculo das raças: cientistas, instituições e questão racial no Brasil - 1870-1930. São Paulo: Cia. das Letras, 1993.

SOARES, Carmen Lúcia. Educação Física: raízes européias e Brasil. São Paulo: Autores Associados, 1994.

Imagens da educação no corpo; estudo a partir da ginástica francesa no século XIX. Campinas: Faculdade de Educação, Unicamp, 1996. (Tese doutorado em Educação.)

SOUSA, Eustáquia Salvadora de. Meninos à marcha, meninas à sombra: a história da Educação Física em Belo Horizonte - 1897/1994. Campinas (SP): Unicamp, (Tese, doutorado em Educação) Universidade de Campinas, 1994.

Movimento, Porto Alegre, v. 10, n. 3, p.77-97, setembro/dezembro de 2004 
SOUZA, Rita de Cássia. A Revista do Ensino e a disciplina escolar em Minas Gerais (1925-1930). Belo Horizonte (MG): UFMG, (Dissertação, mestrado em Educação), Faculdade de Educação da UFMG, 2000.

SOUZA, Rosa de Fátima. Espaço da Educação e da civilização: origens dos Grupos Escolares no Brasil. In: SOUZA, Rosa Fátima \& VALDEMARIN, Vera Teresa \& ALMEIDA, Jane Soares (Orgs.). O legado educacional do século XIX. Araraquara: Unesp, Faculdade de Ciências e Letras, 1998.

Templos de civilização: A implantação da escola primária graduada no Estado de São Paulo (1890-1910). São Paulo: Fundação Editora da Unesp, 1998.

VAGO, Tarcísio Mauro. A escolarização da gymnastica nas escolas normais de Minas Gerais - 1883/1918 In: FERREIRA NETO, Amarílio (Org.). Pesquisa histórica na educação física, n. 2, 1997.

Cultura escolar, cultivo de corpos: Educação Physica e Gymnastica como práticas constitutivas dos corpos de crianças no ensino público primário de Belo Horizonte (1906-1920). Bragança Paulista: Editora da Universidade São Francisco, 2002.

VEIGA, Cynthia Greive. Cidadania e educação na trama da cidade: a construção de Belo Horizonte em fins do século XIX. Campinas, Universidade de Campinas, Faculdade de Educação, 1994. (Tese - doutorado em Educação.)

. \& FARIA FILHO, Luciano M. Belo Horizonte: a escola e os processos educativos no movimento da cidade. Varia Historia, Belo Horizonte, n. 18, set 97.

VIÑAO FRAGO, Antonio. Historia de la educatión e historia cultural: possibilidades, problemas, cuestiones. Revista Brasileira de Educação, São Paulo, n. 0, p. 63-82, set./dez., 1995.

Tiempos escolares, tiempos sociales. La distribuición del tiempo y del trabajo en la enseñanza primaria en España (1838-1936). Barcelona: Anil, 1998.

Do espaço escolar e da escola como lugar: propostas e questões. In ECOLANO, Augustín \& VINAO FRAGO, Antonio. Currículo, espaço subjetividade: a arquitetura como programa. Trad. Alfredo Veiga-Neto. Rio de Janeiro: DP\&A, 1998.

Recebido em: 03/09/2004 Aprovado em: 05/11/2004

Tarcísio Mauro Vago Rua Estanislau Fernandes, 197

Bairro Ouro Preto 31340-130

Belo Horizonte, MG

tmvago@uai.com.br

Movimento, Porto Alegre, v. 10, n. 3, p.77-97, setembro/dezembro de 2004 